\title{
ANALISA GELOMBANG KEJUT PADA LENGAN PERSIMPANGAN TERHADAP ALIRAN ARUS LALULINTAS
}

\author{
Zulfhazli \\ Jurusan Teknik Sipil Universitas Malikussaleh \\ email: zulfhazli.abdullah@gmail.com
}

\begin{abstract}
Abstrak
Gelombang kejut terjadi karena adanya pergantian nyala lampu lalu lintas berwarna merah, kendaraan akan berhenti, kepadatan lengan sebelum lampu merah akan meningkat, kecepatan menurun, dan akhirnya terjadi antrian. Gerakan arus lalu lintas yang terjadi pada saat kondisi lampu merah inilah yang disebut dengan gelombang kejut. Perhitungan ukuran kinerja dan kapasitas jalan Indonesia mengaju pada Manual Kapasitas Jalan Indonesia (MKJI) yang dikeluarkan oleh Departemen Pekerjaan Umum Direktorat Jendral Bina Marga pada tahun 1997. Penelitian ini bertujuan untuk mengetahui hubungan karakteristik lalu lintas, nilai gelombang kejut serta panjang antrian yang di analisa sesuai teori gelombang kejut. Penelitian dilakukan pada lengan persimpang bersinyal. Hasil analisa diperoleh hasil volume lalu lintas paling padat terjadi pada hari Senin pagi dengan volume 9281,2 smp/jam dengan kerapatan 630,04 smp/km, arus maksimum (Vmak) didapat dengan menggunakan model Greenshield terjadi pada pagi hari senin dengan nilai arus 303,58 Smp/Jam, nilai gelombang kejut terbesar dan panjang antrian terpanjang terjadi pada hari rabu dengan nilai gelombang kejut $21,48 \mathrm{~km} / \mathrm{jam}$ dan panjang antrian 197,5 meter. Hal ini menandakan semakin besar nilai gelombang kejut maka semakin besar pula nilai panjang antrian yang didapat.
\end{abstract}

Kata kunci : lalu-lintas, persimpangan, gelombang kejut, greeshield.

\section{Pendahuluan}

Prinsip dasar analisis arus lalu-lintas pada ruas jalan adalah kecepatan berkurang jika arus bertambah. Pengurangan kecepatan akibat penambahan arus adalah kecil pada arus rendah tetapi lebih besar pada arus yang lebih tinggi. Pada keadaan arus bebas, arus kendaraanakan melaju dengan kecepatan tertentu, tetapi bila arus tersebut mendapat gangguan, maka akan terjadinya pengurangan arus dan yang seterusnya akan mengakibatkan kerapatan yang semakin meningkat dan terjadinya pengurangan kecepatan kendaraan sehingga dapat menimbulkan panjang antrian. Kajian penting dalamfenomena perilaku arus lalu-lintas adalah kajian mengenai gelombang kejut dengan menggunakan model greeshield. Gelombang kejut dapat digambarkan sebagai gerakan pada arus lalu-lintas akibat adanya perubahan nilai kepadatan dan arus lalu-lintas.

Sasaran penelitian ini adalah menghasilkan kualitas arus lalu-lintas untuk melewati persimpangan dengan cara memaksimalkan arus lalu-lintas yang lewat dan meminimalkan antrian dan tundaan,dalam keadaan inimaka akan terjadisuatu perubahan kecepatan dan kerapatan yang akan menimbulkan gelombang kejut (shock wave). 


\section{Tinjauan Kepustakaan}

Gelombang Kejut Simpang Bersinyal, menurut Tamin (2003) gelombang kejut pada persimpangan berlampu lalu-lintas dapat dianalisis apabila diketahui hubungan antara arus dengan kerapatan pada lengan persimpangan dan keadaan arus lalu-lintas yang datang pada persimpangan adalah tertentu. Sebagai contoh, kurva arus kecepatan dan keadaan arus lalu-lintas pada lengan persimpangan berada pada keadaan A seperti pada Gambar 1.a. Diagram jarak-waktu yang diperlihatkan pada Gambar 1.b dengan skala jarak dan waktu dipilih sedemikian sehingga kemiringan yang ada pada kedua gambar tersebut dapat mewakili kecepatan kendaraan tertentu atau kecepatan gelombang kejut. Garis henti pada pendekat diwakili oleh pita sinyal dengan warna hijau bertanda polos dan merah bertanda terarsir.

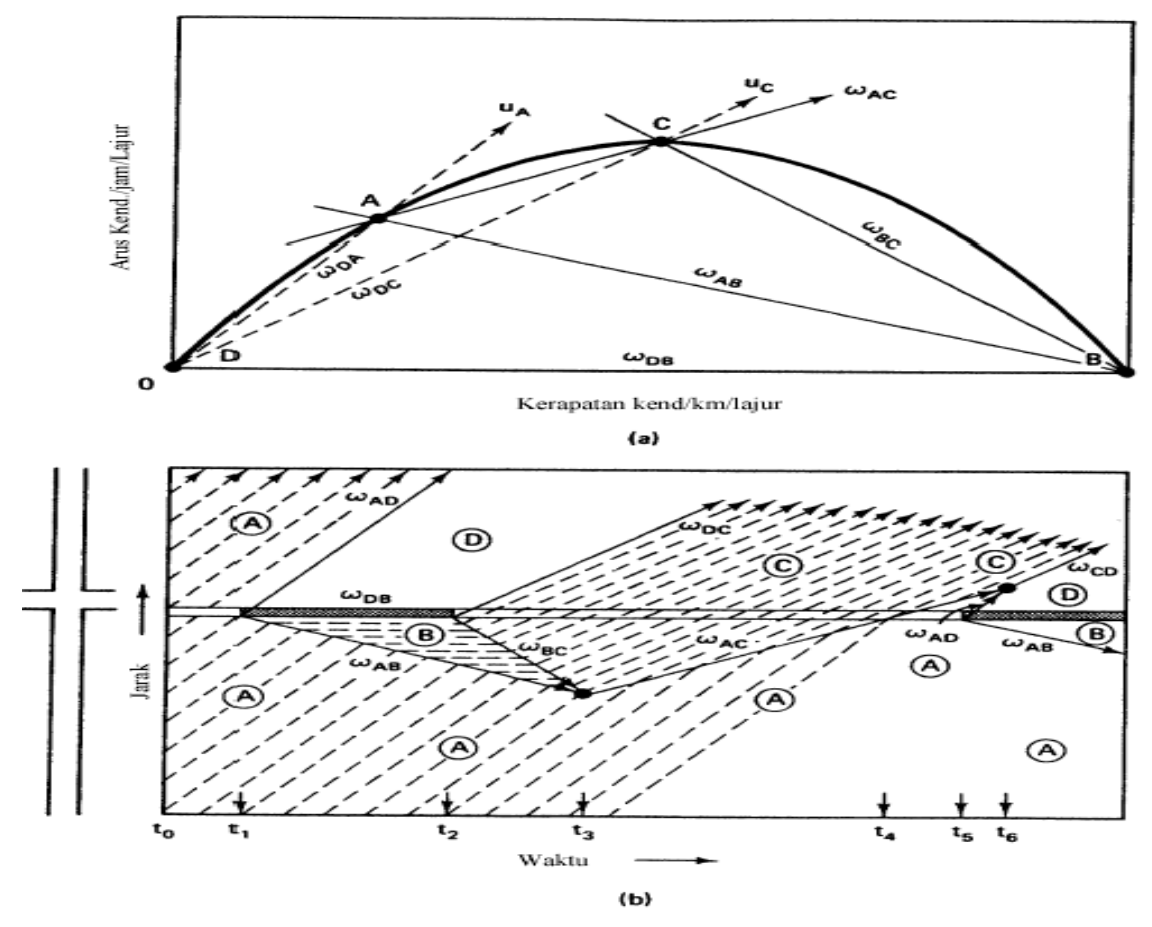

Gambar 1. Gelombang Kejut Pada Persimpangan bersinyal

Selama waktu dari $t_{0}$ ke $t_{1}$, lampu lalu-lintas menyala hijau sehingga lalu lintas pada lengan persimpangan berjalan melewati persimpangan kearah hilir dengan keadaan arus $\mathrm{A}\left(\mathrm{V}_{\mathrm{A}}, \mathrm{D}_{\mathrm{A}}\right.$, dan $\left.\mathrm{S}_{\mathrm{A}}\right)$. Lintasan kendaraan digambarkan sebagai garis putus-putus. Pada saat $t_{1}$ dimana nyala lampu lalulintas berubah menjadi merah, keadaan arus pada arah hulu garis henti segera berubah menjadi keadaan B, sedangkan keadaan arus arah hilir segera berubah menjadi keadaan D.

Ada tiga gelombang kejut mulai terjadi di garis henti pada saat $t_{1}$, yaitu $\omega_{\mathrm{AD}}, \omega_{\mathrm{DB}}$ dan $\omega_{\mathrm{AB}}$. Kecepatan dari ketiga gelombang kejut ini, digambarkan pada Gambar 1.1a yang dapat dihitung menurut rumus berikut: 


$$
\begin{aligned}
& \omega_{A D}=\frac{V_{A}-V_{D}}{D_{A}-D_{D}}=S_{A} \ldots . \\
& \omega_{D E}=\frac{V_{D}-V_{E}}{D_{D}-D_{E}}=0 \\
& \omega_{A D}=\frac{V_{A}-V_{E}}{D_{A}-D_{R}}=\frac{V_{A}}{D_{A}-D_{R}}
\end{aligned}
$$

dimana :

$$
\begin{aligned}
& \omega_{\mathrm{AD}}=\text { kecepatan gelombang kejut dari kondisi arus A ke kondisi arus D } \\
& \quad(\mathrm{km} / \mathrm{jam}) \\
& \left.\mathrm{V}_{\mathrm{A}}=\text { nilai arus pada kondisi arus A ( } \mathrm{smp} / \mathrm{jam} / \mathrm{lajur}\right) \\
& \mathrm{D}_{\mathrm{A}}=\text { kerapatan lalulintas pada kondisi arus A }(\mathrm{smp} / \mathrm{km}) \\
& \mathrm{S}_{\mathrm{A}}=\text { kecepatan lalulintas pada kondisi arus A }(\mathrm{km} / \mathrm{jam})
\end{aligned}
$$

Kondisi arus $\mathrm{A}, \mathrm{B}$, dan $\mathrm{D}$ berlanjut hingga waktu $\mathrm{t}_{2}$, saat mana sinyal berubah manjadi hijau. Suatu arus kondisi baru terjadi yaitu kondisi C pada saat $\mathrm{t}_{2}$, dimana arus di garis henti meningkat dari nol menjadi arus jenuh. Ini mengakibatkan dua gelombang kejut baru yaitu $\omega_{\mathrm{DC}}$ dan $\omega_{\mathrm{BC}}$, sedangkan gelombang kejut $\omega_{\mathrm{DB}}$ berakhir. Kecepatan kedua gelombang kejut ini dapat diketahui dengan cara grafis melalui Gambar 1.1a atau dihitung menurut persamaan berikut:

$$
\begin{aligned}
& \omega_{D C}=\frac{V_{D}-V_{C}}{D_{D}-D_{C}}=S_{C} \\
& \omega_{B C}=\frac{V_{B}-V_{C}}{D_{E}-D_{C}}=\frac{V_{C}}{D_{E}-D_{C}}
\end{aligned}
$$

Kondisi arus $\mathrm{A}, \mathrm{B}, \mathrm{D}$ dan $\mathrm{C}$ ini berlanjut sampai dengan $\omega_{\mathrm{AB}}$ dan $\omega_{\mathrm{BC}}$ mencapai $t_{3}$,selang waktu antara $t_{2}$ dan $t_{3}$ dapat dihitung menurut persamaan berikut dimana $r$ adalah durasi efektif fase merah dalam satuan waktu detik:

$$
t_{3}-t_{2}-r\left(\frac{\omega_{A B}}{\omega_{B C}-\omega_{A B}}\right)(\text { detik })
$$

Pada waktu $t_{3}$, terjadi gelombang kejut baru $\omega_{\mathrm{AC}}$, sedangkan dua gelombang kejut $\omega_{\mathrm{AB}}$ dan $\omega_{\mathrm{BC}}$ berakhir. Nilai $\omega_{\mathrm{AC}}$ dapat dihitung dengan persamaan:

$$
\omega_{A C}=\frac{V_{A}-V_{C}}{D_{A}-D_{C}}
$$

Kondisi arus D, C dan A berlanjut sampai dengan waktu $t_{5}$, dimana fase hijau berubah menjadi fase merah,namun sebelum sampai waktu $t_{5}$, gelombang kejut $\omega_{A C}$ memotong garis henti pada waktu $t_{4}$, saat mana arus maksimum $V_{C}$ (kondisi $\mathrm{C}$ ) berubah menjadi arus datang $\mathrm{V}_{\mathrm{A}}$ (kondisi $\mathrm{A}$ ) pada garis henti. Periode waktu dari mulainya fase hijau sampai menurunnya volume arus pada garis adalah nilai maksimum $\mathrm{t}_{2} \mathrm{ke}_{4}$ dan dapat dihitung sebagai berikut: 


$$
t_{4}-t_{2}=\frac{r\left(\omega_{A E}\right)}{\omega_{B C}-\omega_{A B}}\left(\frac{\omega_{E C}}{\omega_{A C}}+1\right)(\text { detik })
$$

Pada waktu $\mathrm{t}_{5}$, dengan dimulainya fase merah, pola gelombang kejut ke arah hulu dari lampu lalu lintas mulai berulang lagi. Tetapi pola gelombang kejut arah hilir dari lampu lalu lintas menyimpang dari pola awal. Perhatikan bahwa pada awal fase merah, gelombang kejut $\omega_{\mathrm{AD}}$ mulai terbentuk, tetapi berjalan ke arah hilir hanya sampai bertemu dengan gelombang kejut $\omega_{\mathrm{AC}}$. Pada waktu $\mathrm{t}_{6}$, di mana gelombang kejut $\omega_{\mathrm{AD}}$ dan $\omega_{\mathrm{AC}}$ berakhir, gelombang kejut baru $\omega_{\mathrm{CD}}$ terbentuk. Untuk seterusnya, sepanjang arus lalulintas dan waktu siklus tidak berubah, pola gelombang kejut akan berulang setiap siklus lampu lalulintas.

\section{Metode Penelitian}

Data primer yaitu data yang diperoleh langsung dari pengamatan di lapangan, meliputi:

a) Data geometric meliputi lebar jalan, bahu jalan, lebar lajur, lebar lengan persimpangan, danlebar median.

b) Data lalu-lintas berupada volume lau-lintas dan kecepatan

c) Data sinyal lampu lalu-lintas dilakukan per siklus selama masa survei persimpangan. Pengambilan data sinyal lampu lalu-lintas dilakukan bersama dengan data arus pada persimpangan. Data yang diperlukan adalah jumlah dan pola fase beserta waktu fase (merah, hijau, dan kuning) setiap siklus.

Data sekunder adalah data yang diperoleh dari beberapa instansi terkait termasuk beberapa penelitian tentang persimpangan yang diteliti sebelumnya. Data sekunder berupa Peta jaringan Kota Lhokseumawe.

\section{Hasil dan Pembahasan}

\subsection{Hasil}

\subsubsection{Volume lalu-lintas}

Hasil penelitian di lapangan diperoleh volume lalu-lintas terbesar Jalan Merdeka arah masuk yaitu hari Senin pagi sebesar $9281 \mathrm{smp} / \mathrm{jamdan}$ volume lalu lintas terbesar Jalan Merdeka arah keluar Kota Lhokseumawe yaitu hari Minggu sore sebesar $6132,8 \mathrm{smp} / \mathrm{jam}$.

\subsubsection{Kecepatan}

Kecepatan rata-rata tiap tipe kendaraan didapat dari jumlah jarak yang ditempuh dibagi dengan jumlah waktu tempuh,sedangkan waktu tempuh kendaraan diperoleh dari selisih antara waktu masuk dengan waktu keluar persimpangan jalan yang diteliti. Hasil kecepatan rata-rata yang diperoleh di lapangan adalah 19,73 km/jam pada hari Senin, 18,94 km/jam pada hari Rabu dan $30,84 \mathrm{~km} / \mathrm{jam}$ pada hari Minggu.

\subsubsection{Kerapatan Kendaraan}

Kerapatan dapat dihitung dengan menggunakan persamaan $\mathrm{k}=\mathrm{q} / \mathrm{Us}$ dimana $\mathrm{k}=$ kerapatan kendaraan, $\mathrm{q}=$ arus dan $\mathrm{Us}=$ kecepatan rata-rata kendaraan,seperti halnya pada tabulasi data arus dan kecepatan, kerapatan juga dibuat untuk interval 15 menitan pada setiap jalur. 


\subsubsection{AnalisisisModel Greenshield}

Hasil analisis melalui pendekatan model Greenshield dengan menggunakan perangkat lunak Microsoft Excel, maka diperoleh model hubungan antar karakteristik volume (q), kecepatan (v), kerapatan (k) dan volume maksimum (Vmax) diperlihatkan pada Tabel 1 dan Tabel 2.

Tabel 1. Hubungan Matematis Antara Kecepatan dan Kepadatan

\begin{tabular}{|c|c|c|c|}
\hline Periode & Pagi & Siang & Sore \\
\hline Pengamatan & $(07.00-09.00)$ & $(12.00-14.00)$ & $(15.00-17.00)$ \\
\hline \multirow{2}{*}{ Senin } & Us $=15,42-0,1958$ & Us $=19,17-$ & Us $=24,59-$ \\
& $* \mathrm{D}$ & $0,344 * \mathrm{D}$ & $0,521 * \mathrm{D}$ \\
\hline \multirow{2}{*}{ Rabu } & Us $=19,41-$ & Us $=18,63-$ & Us $=18,80-$ \\
& $0,3383 * \mathrm{D}$ & $0,317 * \mathrm{D}$ & $0,358 * \mathrm{D}$ \\
\hline \multirow{2}{*}{ Minggu } & Us $=29,75-$ & Us $=32,03-$ & Us $=30,74-$ \\
& $1,606 * \mathrm{D}$ & $2,296 * \mathrm{D}$ & $1,180 * \mathrm{D}$ \\
\hline
\end{tabular}

Tabel 2. Hubungan Matematis Antara Volume dan Kecepatan

\begin{tabular}{|c|c|c|c|}
\hline Periode & Pagi & Siang & Sore \\
\hline Pengamatan & $(07.00-09.00)$ & $(12.00-14.00)$ & $(15.00-17.00)$ \\
\hline Senin & $\begin{array}{c}\mathrm{V}=78,75 . \mathrm{Us}-5,107 \\
. \mathrm{Us}^{2}\end{array}$ & $\begin{array}{c}\mathrm{V}=55,61 . \mathrm{Us}- \\
2,900 . \mathrm{Us}^{2}\end{array}$ & $\begin{array}{c}\mathrm{V}=47,11 . \mathrm{Us}- \\
2,457 . \mathrm{Us}^{2}\end{array}$ \\
\hline Rabu & $\begin{array}{c}\mathrm{V}=57,37 . \mathrm{Us}-2,955 \\
. \mathrm{Us}^{2}\end{array}$ & $\begin{array}{c}\mathrm{V}=58,62 . \mathrm{Us}- \\
3,146 . \mathrm{Us}^{2}\end{array}$ & $\begin{array}{c}\mathrm{V}=52,48 . \mathrm{Us}- \\
2,786 . \mathrm{Us}^{2}\end{array}$ \\
\hline Minggu & $\begin{array}{c}\mathrm{V}=18,52 . \mathrm{Us}-0,622 \\
. \mathrm{Us}^{2}\end{array}$ & $\begin{array}{c}\mathrm{V}=13,95 . \mathrm{Us}- \\
0,435 . \mathrm{Us}^{2}\end{array}$ & $\begin{array}{c}\mathrm{V}=26,05 . \mathrm{Us}- \\
0,847 . \mathrm{Us}^{2}\end{array}$ \\
\hline
\end{tabular}

Berdasarkan hasil analisis karakteristik kenderaan dengan menggunakan model Greenshield, didapat bahwa hari Senin pagi arah Masuk Kota Lhokseumawe merupakan volume maksimum yang terbesar terjadi yaitu Vmax sebesar 303,58 smp/jam/lajur sedangkan pada arah keluar Kota Lhokseumawe volume maksimum terjadi pada hari Minggu Sore yaitu Vmax sebesar 191,51 Smp/Jam/lajur.

Tabel 3. Hubungan Matematis Antara Volume dan Kepadatan

\begin{tabular}{|c|c|c|c|}
\hline Periode & Pagi & Siang & Sore \\
\hline Pengamatan & $(07.00-09.00)$ & $(12.00-14.00)$ & $(15.00-17.00)$ \\
\hline \multirow{2}{*}{ 23-Feb-15 } & $\mathrm{V}=15,42 . \mathrm{D}-$ & $\mathrm{V}=19,17 . \mathrm{D}-0,344$ & $\mathrm{~V}=24,59 . \mathrm{D}-$ \\
& $0,1958 . \mathrm{D}^{2}$ &. $\mathrm{D}^{2}$ & $0,521 . \mathrm{D}^{2}$ \\
\hline \multirow{2}{*}{ 25-Feb-15 } & $\mathrm{V}=19,41 . \mathrm{D}-$ & $\mathrm{V}=18,63 . \mathrm{D}-$ & $\mathrm{V}=18,80 . \mathrm{D}-$ \\
& $0,3383 . \mathrm{D}^{2}$ & $0,317 . \mathrm{D}^{2}$ & $0,358 . \mathrm{D}^{2}$ \\
\hline \multirow{2}{*}{ 01-Mar-15 } & $\mathrm{V}=29,75 . \mathrm{D}-$ & $\mathrm{V}=32,03 . \mathrm{D}-$ & $\mathrm{V}=30,74 . \mathrm{D}-$ \\
& $1,606 . \mathrm{D}^{2}$ & $2,296 . \mathrm{D}^{2}$ & $1,180 . \mathrm{D}^{2}$ \\
\hline
\end{tabular}




\subsection{Gelombang Kejut dan Panjang Antrian}

C

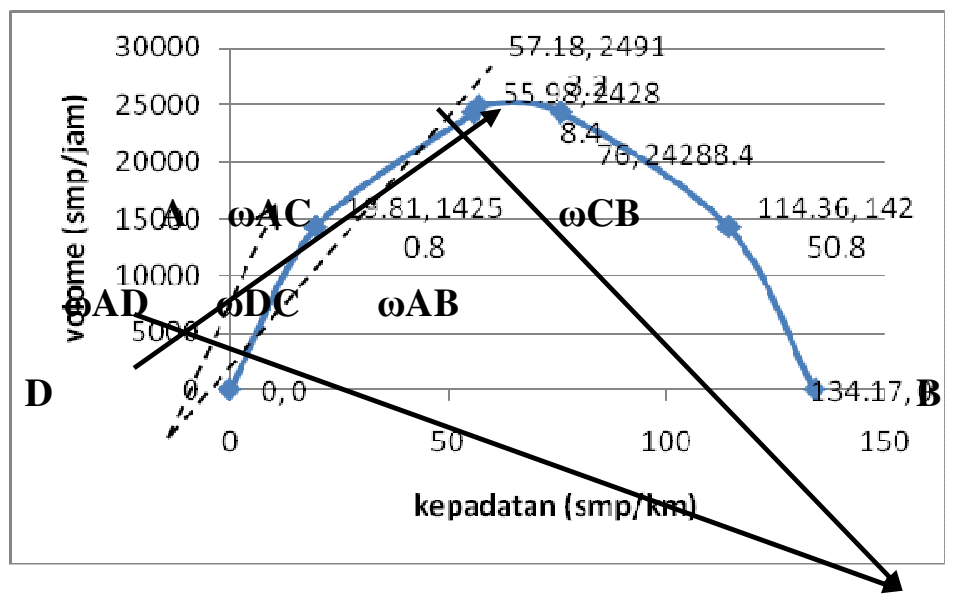

Gambar 2.Hubungan matematis Persimpangan jalan masuk

$\omega \mathrm{AC}$

$\omega B C$

$\omega \mathbf{D A}$

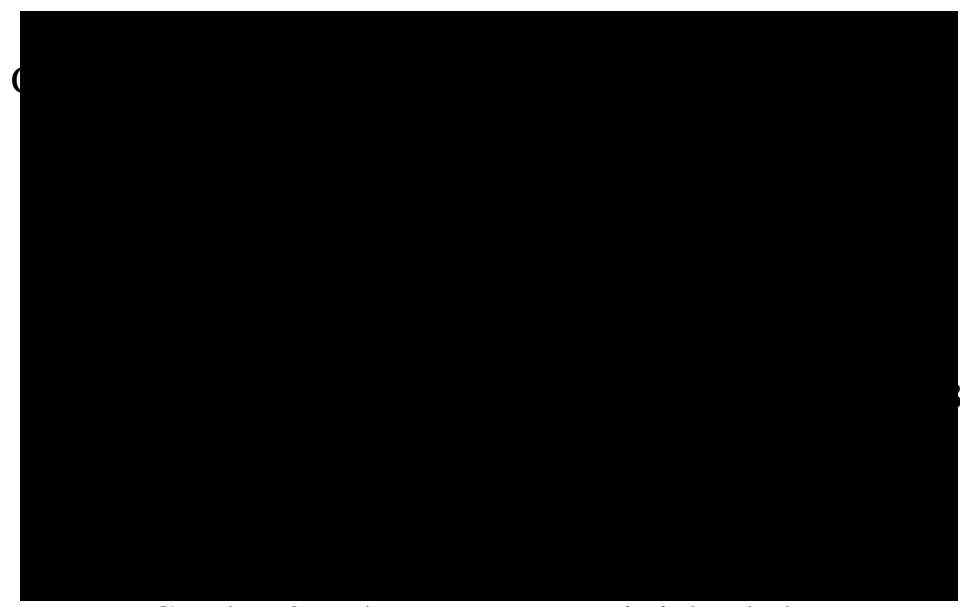

Gambar 2.Hubungan matematis jalan keluar

\subsection{Pembahasan}

Berdasarkan hasil survei pada penelitian ini dapat dilihat dari hasil perhitungan dan hasil pengamatan di lapangan bahwa panjang antrian yang dihitung sesuai dengan rumus gelombang kejut, berbeda dengan panjang antrian yang diamati di lapangan. Dari arus lalu-lintas yang terjadi, terlihat adanya pola jam puncak sepanjang waktu penelitian yaitu pada pagi hari terutama pada hari Rabu.

Gelombang kejut yang terjadi baik pada persimpangan berlampu lalu-lintas maupun pada ruas jalan yang terhambat berpengaruh terhadap pergerakan kendaraan, keadaan ini diperlihatkan dengan terjadinya antrian, semakin besar nilai gelombang kejut, maka semakin panjang pula antrian yang terjadi pada lengan persimpangan jalan yang diteliti. Grafik hubungan antara gelombang kejut dan panjang antrian dapat dilihat pada Gambar 3. 


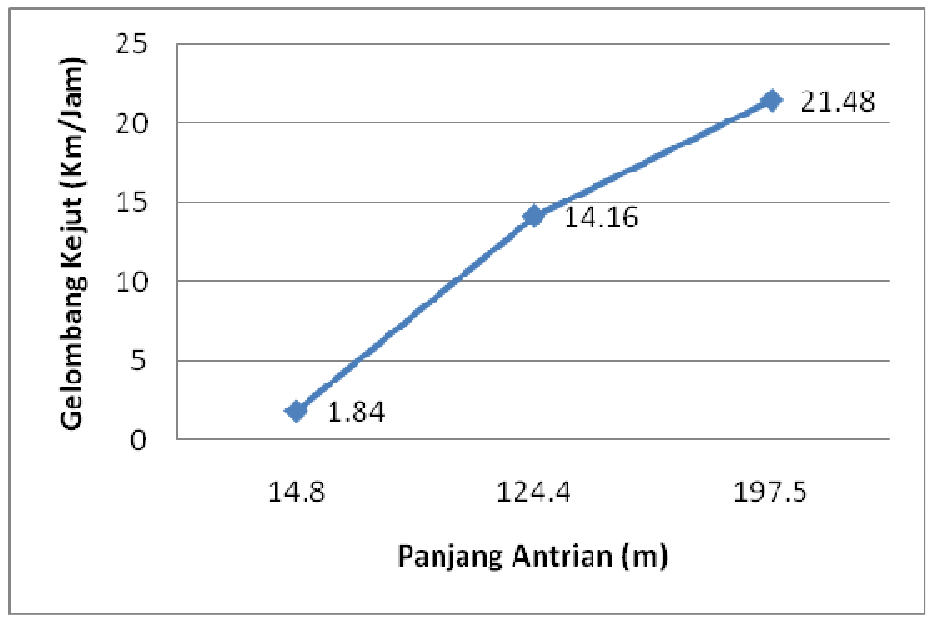

Gambar 3.Grafik Hubungan Gelombang Kejut dan Panjang Antrian

\section{Kesimpulan dan Saran}

\subsection{Kesimpulan}

Dari hasil penelitian dan pembahasan dapat diambil beberapa kesimpulan sebagai berikut:

1. Volume lalulintas yang paling padat lengan persimpanganarah masuk terjadi pada hari Senin Pagi dengan nilai 9281,2 smp/jam dengan kerapatan 630,04 smp/km sedangkan volume yang paling padat lengan persimpanganarah keluar terjadi pada hari Minggu Sore dengan nilai 6132,8 smp/jam dengan kerapatan 199,22 smp/km. Hal ini menandakan semakin besar volume maka semakin berkurangnya kecepatan dan semakin meningkatnya kerapatan.

2. Gelombang kejut terbesar dan panjang antrian terpanjang terjadi pada hari Rabu dengan nilai gelombang kejut 21,48 km/jam dan panjang antrian 197,5 meter. Hal ini menandakan semakin besar nilai gelombang kejut maka akan semakin besar juga panjang antrian yang didapat

3. Nilai gelombang kejut sangat berpengaruh terhadap waktu sinyal traffic light, sehingga semakin besar waktu sinyal yang diberikan maka semakin besar nilai gelombang kejut yang didapat dan semakin besar pula panjang antrian yang didapat.

\subsection{Saran}

Dari kesimpulan yang dipaparkan diatas, terdapat beberapa saran yang diusulkan, diantaranya adalah:

1. Perlu dicari faktor-faktor lain yang mempengaruhi kecepatan, kerapatan dan arus lalu lintas pada lokasi yang ingin diteliti, misalkan derajat kejenuhan, tundaan dan lain-lain.

2. Sebaiknya ditambahkan beberapa metode lagi guna perbandingan agar mendapatkan hasil yang lebih baik, misalkan Metode Greenberg dan Metode Underwood. 


\section{Daftar Kepustakaan}

Ansyori Alamsyah, Alik, 2005, Rekayasa Lalu Lintas, Malang, UMM Press, Malang.

Budi Utomo, Heri, 1998, Analisis Gelombang Kejut Pada Jalan Bebas Hambatan dan Persimpangan Berlampu Lalu Lintas, http://www.google.com, Theses. diunduh tanggal 25 November 2011.

Direktorat Jenderal Bina Marga, 1997, Manual Kapasitas Jalan Indonesia, Departemen Pekerjaan Umum, Indonesia

Http://www.google.com

Idham, Muhammad, 2000, Analisis Gelombang Kejut Pada Persimpangan Berlampu Lalu Lintas, http://www.google.com, Journal. diunduh tanggal 15 Desember 2014.

Kasan, Muhammad, 1999, Aplikasi Teori Gelombang Kejut Dalam Penentuan Panjang Antrian Kendaraan Pada Lengan Persimpangan Bersinyal, http://www.google.com, Theses. diunduh tanggal 1 Desember 2011.

Morlock, E. K.. 1991, Pengantar Teknik dan Perencanaan Transportasi, Jakarta: Erlangga

Tamin, Ofyar Z, 2003, Perencanaan dan Pemodelan Transportasi Contoh Soal dan Aplikasi Edisi Kesatu, ITB, Bandung 